Georgia State University

ScholarWorks @ Georgia State University

\title{
Schizotypy and Nicotine, Alcohol, and Cannabis Use in a Non- Psychiatric Sample
}

\author{
Michael L. Esterberg \\ Graduate School of Arts and Sciences of Emory University, Department of Psychology \\ Sandra M. Goulding \\ Emory University School of Medicine, Department of Psychiatry and Behavioral Sciences \\ Erin B. McClure-Tone \\ Georgia State University, Department of Psychology, etone@gsu.edu \\ Michael T. Compton \\ Emory University School of Medicine, Department of Psychiatry and Behavioral Sciences
}

Follow this and additional works at: https://scholarworks.gsu.edu/psych_facpub

Part of the Psychology Commons

\section{Recommended Citation}

Esterberg, Michael L.; Goulding, Sandra M.; McClure-Tone, Erin B.; and Compton, Michael T., "Schizotypy and Nicotine, Alcohol, and Cannabis Use in a Non-Psychiatric Sample" (2009). Psychology Faculty Publications. 131.

https://scholarworks.gsu.edu/psych_facpub/131

This Article is brought to you for free and open access by the Department of Psychology at ScholarWorks @ Georgia State University. It has been accepted for inclusion in Psychology Faculty Publications by an authorized administrator of ScholarWorks @ Georgia State University. For more information, please contact scholarworks@gsu.edu. 
Schizotypy and Nicotine, Alcohol, and Cannabis Use in a Non-Psychiatric Sample

Michelle. L. Esterberg, M.P.H., M.A.

Sandra M. Goulding, M.P.H. ${ }^{\mathrm{b}}$

Erin B. McClure-Tone, Ph.D. ${ }^{\mathrm{C}}$

Michael T. Compton, M.D., M.P.H. ${ }^{\mathrm{b}}$

${ }^{a}$ Graduate School of Arts and Sciences of Emory University, Department of Psychology

${ }^{\mathrm{b}}$ Emory University School of Medicine, Department of Psychiatry and Behavioral Sciences

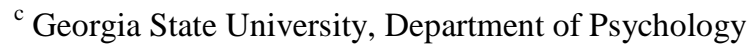

Addresses:

Emory University Graduate School of Arts and Sciences

Department of Psychology

1462 Clifton Road, Suite 235

Atlanta, GA $30322^{\mathrm{a}}$

Emory University School of Medicine

Department of Psychiatry and Behavioral Sciences

49 Jesse Hill Jr. Drive, S.E.

Atlanta, GA $30303^{\text {b }}$

Georgia State University

Department of Psychology

P.O. Box 5010

Atlanta, GA 30302-5010 c

Email Addresses:

Michelle. L. Esterberg: mesterb@emory.edu

Sandra M. Goulding: sandra.m.goulding@emory.edu

Erin B. McClure-Tone: psyebm@langate.gsu.edu

Michael T. Compton: mcompto@emory.edu 


\section{Corresponding Author}

Michelle L. Esterberg, M.P.H., M.A.

Emory University Graduate School of Arts and Sciences

Department of Psychology

1462 Clifton Road, Suite 235

Atlanta, GA 30322

TEL: 404-727-7547 / FAX: 404-727-1284

E-MAIL: mesterb@emory.edu 


\begin{abstract}
Schizotypy is a multidimensional personality construct that is characterized by perceptual abnormalities, social withdrawal, mild suspiciousness, and odd thinking patterns. This study examined the relationship between four dimensions of self-reported schizotypy and substance use involving nicotine, alcohol, and cannabis, in undergraduate students. Results showed that higher levels of disorganized schizotypy, or odd thinking and behavior, were associated with greater indices of use of all three substances. Furthermore, higher cognitive-perceptual schizotypy was selectively associated with cannabis use. Results confirm findings of recent research that has discovered associations among schizotypy and substance use, highlighting links between behavioral traits and use of nicotine, alcohol, and cannabis. This study is one of the first to examine a wide range of schizotypy domains, and to show selective effects of the disorganized domain of schizotypy.
\end{abstract}

Key Words: Alcohol; Cannabis; Nicotine; Schizotypal Personality Questionnaire; Schizotypy; Substance abuse 


\subsection{Introduction}

Schizotypy is a multifaceted personality profile of great interest to personality and schizophrenia researchers alike. The schizotypy construct encompasses a set of dimensional traits in behavioral, perceptual, ideational, cognitive, and affective domains that exist along continua in the general population (Raine, Lencz, \& Mednick, 1995). Biological relatives of individuals with schizophrenia are more likely to exhibit schizotypal traits than those without a family history of the illness (Kendler, McGuire, Gruenberg, \& Walsh, 1995), suggesting that schizotypy is genetically related to schizophrenia. Individuals with schizotypal personality features exhibit social deficits similar to, but less prominent than, those found in schizophrenia (Dickey et al., 2005).

Investigators have long been interested in the high prevalence of substance use in individuals with schizophrenia, given that up to $50 \%$ of individuals with schizophrenia have a co-occurring substance use disorder (Dixon, 1999). In light of the relationship between schizophrenia and schizotypy, lines of investigation have more recently turned toward examining associations between schizotypy and substance use. Some research in the general population has shown that greater levels of schizotypy are related to cigarette, alcohol, and cannabis use. Regarding the use of cigarettes, Allan and colleagues (1995) found a positive correlation between self-reported schizotypy and a measure of the number of cigarettes smoked per day. Other studies have revealed similar results (Joseph, Manafi, Iakovaki, \& Cooper, 2003; Larrison, Briand, \& Sereno, 1999; Wiles et al., 2006). A recent study in this area of research examined the relationship between cigarette use and schizotypy in a sample of healthy adults and relatives of patients with schizophrenia (Esterberg, Jones, Compton, \& Walker, 2008). Individuals who 
smoked had greater levels of schizotypy; however, the relationship was significant only among the relatives of patients with schizophrenia.

Schizotypy has also been examined in relation to use of alcohol. Rather than a global positive relationship between the two, results suggest a more nuanced pattern of associations between alcohol use and specific domains of schizotypy. Nunn and colleagues (2001), for example, found that alcohol use in a sample of undergraduate students was related to lower introvertive anhedonia, or negative schizotypy, and to higher scores on delusional conviction, a construct similar to positive schizotypy. Larrison et al. (1999) found that increased alcohol use was associated with lower scores on the Rust Inventory of Schizotypal Cognitions (RISC; Rust, 1998), a measure of positive schizotypy. There have been $n$ No other published studies conducted that have examined the relationship between schizotypy and alcohol use in the general population.

An emerging body of research suggests an association between schizotypy and cannabis use (Compton, Goulding, \& Walker, 2007). Several studies involving university students have demonstrated correlations between cannabis use and positive schizotypal symptomatology in particular (Bailey \& Swallow, 2004; Dumas et al., 2002; Mass, Bardong, Kindl, \& Dahme, 2001; Nunn, Rizza, \& Peters, 2001; Schiffman, Nakamura, Earleywine, \& LaBrie, 2005; Skosnik, Krishnan, Aydt, Kuhlenshmidt, \& O’Donnell, 2006). One study found a significant positive correlation between schizotypy scores and total self-reported years of cannabis use (Skosnik et al., 2006), and another showed that in individuals reporting cannabis use, average age of onset of schizotypal symptoms preceded the age of initiation of cannabis use (Schiffman et al., 2005). Bailey and Swallow (2004) found a broader set of associations between cannabis use and the presence of positive, negative, and disorganized schizotypal characteristics among 60 
undergraduates. However, some studies have suggested that individuals who use cannabis have lower negative schizotypal symptomatology than those not using the drug (Nunn et al., 2001; Schiffman et al., 2005).

Given the relative dearth of literature that has examined the relationship between schizotypy and substance use in large non-psychiatric samples, and the importance of emerging research in this area, this study examined associations between four domains of self-reported schizotypy (cognitive-perceptual, paranoid, negative, and disorganized) and the use of nonprescription substances of abuse (nicotine, alcohol, and cannabis) in a non-psychiatric sample of undergraduate college students at a large, urban university. This study attempted to elucidate

how personality factors such as schizotypy potentially drivepredict -substance use behaviors, which has important implications for public health theory. Understanding more about the predictors of substance use is vital for the development of prevention and treatment efforts, especially in light of recent research that has shown that interventions targeting personality factors significantly reduce use of substances such as alcohol (Conrod, Castellanos, \& Mackie, 2008).

\subsection{Method}

\subsection{Participants}

Participants consisted of a non-clinical sample $(n=950)$ of undergraduate college students enrolled in classes at an urban state university in the southeastern United States. Students enrolled in introductory psychology classes from January 2007 to December 2007 were eligible for participation. Only those students between the ages of 18 and 26 years who spent at least 20 minutes completing the survey were included in the analyses, resulting in a final sample size of 
$n=825$. Not all participants completed all measures; therefore, the total number of participants included in the different analyses varied across statistical tests.

\subsection{Procedure}

Students were invited to participate via a recruitment statement on an experiment management system, which is an online program used to manage the undergraduate research pool at the university. Interested students were required to read an IRB-approved online consent form before proceeding to the questionnaire, which implied their consent to participate. Participants anonymously completed a confidential, web-based survey, and received course credit in return for participation. Automated data entry produced computerized survey data files for data cleaning and data analysis.

\subsection{Measures}

The Schizotypal Personality Questionnaire (SPQ; Raine, 1991) is a 74-item self-report measure that is modeled on the nine criteria of schizotypal personality disorder as defined by the Diagnostic and Statistical Manual of Mental Disorders, Third Edition, Revised. The SPQ total scale score ranges from 0 to 74 , given that each positively endorsed item counts one point. A confirmatory factor analysis (Compton, Goulding, McClure-Tone, \& Bakeman, 2008) of the nine SPQ subscales with the sample in the current investigation revealed a best-fit model of four factors: cognitive-perceptual (odd beliefs and perceptual abnormalities); paranoid (ideas of reference, suspiciousness, and excessive social anxiety); negative (suspiciousness, excessive social anxiety, and constricted affect); and disorganized (eccentric behavior and odd speech). These four factors were used in all analyses.

Participants were also asked to provide information about their substance use histories with regard to three substances: nicotine (cigarette smoking), alcohol, and cannabis. For each 
substance, they were asked: (1) whether or not they had ever used the substance (i.e., lifetime use); (2) if so, their age in years at first use; (3) whether or not they had used the substance in the past 90 days; and (4) if so, the average number of days (range=0-7) per week they had used the substance in the past 90 days. Individuals who reported lifetime use of cigarettes, alcohol, or cannabis were included in subsequent analyses with respect to their age at first use of the substance, whether or not they had used in the past 90 days, and their average daily use of the substance in the past 90 days.

\subsection{Data Analysis}

The relationships among the four factors of the SPQ and the substance use variables were examined using linear and logistic regression analyses, with age and sex included as covariates as appropriate, based on preliminary correlation analyses and $t$-tests. The four factors of the SPQ served as predictors of substance use, and each of the substance use variables served as dependent variables; this resulted in a total of twelve regression analyses. To limit the number of statistical analyses performed, the four factors of the SPQ were entered into one step of each regression model. Although the four SPQ subscales were moderately correlated, the large sample size and a subsequent examination of variance inflation factors, tolerance statistics, and confidence interval widths for each of the regression models safeguarded against the effects of potential multicollinearity.

\subsection{Results}

Table 1 provides sociodemographic characteristics of the sample as well as details regarding schizotypy and substance use. The average age of participants was $20.1 \pm 1.7$ years, and over three-quarters $(637,77.2 \%)$ were female. The large percentage of females was attributed to participants being recruited from an undergraduate introductory psychology course, 
in which the majority of students tend to be female. Nearly half of the students (383, 46.4\%) self-identified as White/Caucasian, 254 (30.8\%) as Black/African American, 84 (10.2\%) as Asian American, and 104 (12.6\%) as of other races. The mean scores for the total SPQ, cognitive-perceptual, paranoid, negative, and disorganized factors were $22.98 \pm 13.61$ (range = 0-74), $3.95 \pm 3.41$ (range=0-16), $9.77 \pm 5.60$ (range=0-25), $9.94 \pm 6.80$ (range=0-33), and 5.26 \pm 4.07 (range $=0-16$ ), respectively.

In preliminary analyses, relationships between several demographic characteristics and the substance use variables were examined. Student's $t$-tests indicated that participants who reported lifetime use of cigarettes, alcohol, or cannabis, as well as use of alcohol or cannabis during the past 90 days, were more likely to be older than non-users. Pearson product moment correlations showed that age was also positively correlated with age at first use of alcohol and cannabis, as well as with average number of days per week that alcohol was used during the past 90 days. T-test results indicated that substance use differed between the sexes as well. Specifically, males were more likely than females to have used cannabis in the past 90 days, and to have used cannabis more frequently during the past 90 days. Given these findings, age and sex were entered as covariates in the regression models predicting substance use.

Preliminary analyses also examined the-correlations and relationships-within the four schizotypy domains and within-among the substance use variables (Tables 2 and 3). As expected, these results showed moderate to large correlations among the four schizotypy domains as well as the twelve variables of substance use, with most relationships being statistically significant. However, as previously mentioned, the large sample size assisted in controlling for multicollinearity, although additional drug use was not controlled for during analyses of the effects on each individual drug to avoid removal of statistical effects.

Comment [EM3]: This sentence isn't clear to me. It sounds as if you're saying 2 conflicting things: 1 ) we worried less about multicollinearity because of the large sample, and 2) we didn't include drugs as covariates for each other for fear of losing power. These seem to be 2 separate ideas-I suggest breaking this into 2 sentences. 
A logistic regression revealed that a model containing all four factors of the SPQ significantly predicted lifetime use of cigarettes (Table 4). However, only the disorganized factor of the SPQ was a significant independent predictor, such that higher levels of disorganized schizotypy were predictive of ever having smoked. A separate logistic regression showed that a model containing all four factors also significantly predicted use of cigarettes in the past 90 days; the disorganized factor was a significant predictor. Again, higher scores on the disorganized factor significantly predicted cigarette use during the past 90 days. A linear regression revealed that a model containing the four SPQ factors did not significantly predict age at first use of cigarettes (Table 4). Finally, a separate linear regression showed that a model containing the four SPQ factors significantly predicted average daily use of cigarettes over the past 90 days, explaining $2 \%$ of the variance above and beyond age and sex. Within the model, only the disorganized factor was a significant individual predictor. Again, higher scores on the disorganized factor predicted greater average daily use of cigarettes.

A logistic regression revealed that a model including all four schizotypy domains did not significantly predict lifetime use of alcohol (Table 5); however, within the model, the disorganized schizotypy factor was a significant individual predictor. A separate logistic regression showed a model including all four factors also did not significantly predict use of alcohol in the past 90 days. However, the disorganized factor was individually predictive of alcohol use during the past 90 days. A linear regression revealed that a model with all four schizotypy factors did not significantly predict age at first use of alcohol, explaining only $1 \%$ of the variance (Table 5). Finally, a separate linear regression showed that a model including the four schizotypy domains significantly predicted average daily use of alcohol over the past 90 
days, explaining $4 \%$ of the variance. The disorganized factor was again a significant individual predictor, with greater disorganization predicting greater average daily use of alcohol.

Lastly, a logistic regression revealed that a model containing all four factors of the SPQ significantly predicted lifetime use of cannabis (Table 6). The disorganized factor of the SPQ was a significant individual predictor, such that higher levels of disorganized schizotypy were predictive of ever having used cannabis. A separate logistic regression showed that a model containing all four factors also significantly predicted cannabis use in the past 90 days; the disorganized factor was again a significant individual predictor. Similar to the effects seen regarding use of cigarettes and alcohol, higher scores on the disorganized factor significantly predicted cannabis use during the past 90 days. A linear regression revealed that a model containing the four SPQ factors did not significantly predict age at first use of cannabis (Table 6), explaining only $2 \%$ of the variance, and there were no significant individual predictors. Finally, a separate linear regression showed that a model containing the four SPQ factors significantly predicted average daily use of cannabis over the past 90 days, explaining 3\% of the variance. Both the cognitive-perceptual and disorganized factors were significant individual predictors. Higher scores on both factors predicted greater average daily use of cannabis.

\subsection{Discussion}

This study provided descriptive information regarding various domains of schizotypy and substance use behaviors in a sample of undergraduate university students. Results showed that the overall level of schizotypy in this sample was comparable to that found in other normative samples that have included individuals of all ages, with studies reporting an average total SPQ score of around 24 (Hall \& Habbits, 1996; Raine, 1991). Furthermore, results on $\underline{\text { rates of }}$ substance use in this sample showed rates of use that awere similar to those reported by the most 
recent National Survey on Drug Use and Health for individuals ages 12 and older (SAMHSA, 2008). However, use of cannabis in the past 90 days was slightly higher, at $22.4 \%$ of the sample, compared to $14.4 \%$ reporting use in the past month on the national health survey.

Results from the current analyses indicate that the disorganized factor of the SPQ had a significant and widespread association with substance use in this sample, such that higher disorganized schizotypy predicted greater likelihood of using substances and younger age at onset of substance use. Results also showed that the cognitive-perceptual factor had selective associations with substance use in this sample, such that it was significantly related to the use of cannabis. There was no evidence that the paranoid and negative factors had any relationship with use of any of the substances. However, with respect to the differential impact of various domains on particular substances, these findings should be interpreted with caution given the moderate correlations between use of nicotine, alcohol, and cannabis.

Regarding nicotine, past research has shown that individuals who smoke cigarettes report higher levels of schizotypy than do individuals who do not smoke (Allan et al., 1995; Joseph et al., 2003; Larrison et al., 1999; Wiles et al., 2006). The current study examined four domains of schizotypy rather than a total composite score including all domains, and results showed that individuals with higher disorganized schizotypy were more likely to report lifetime use of cigarettes, to have used cigarettes during the past 90 days, and to have used cigarettes more frequently during the past 90 days. Esterberg et al. (2008) also found that individuals who smoked cigarettes had higher scores on the disorganized factor of the SPQ; however, this relationship was only significant in relatives of patients with schizophrenia and not in nonpsychiatric adult controls. Although the current study did not collect information on participants' family history of mental illness, it is the first to reveal a relationship between a 
specific domain of schizotypy, namely disorganized schizotypy, and cigarette smoking in a nonpsychiatric sample.

Levels of disorganized schizotypy in this undergraduate sample also predicted lifetime use of alcohol, use of alcohol in the past 90 days, and greater average daily use of alcohol during the past 90 days. Past research has found alcohol use to relate to lower scores on measures of negative schizotypy (Nunn et al., 2001), delusional conviction, and positive schizotypy (Larrison et al., 1999). This is likely related to the social nature of alcohol use, especially in undergraduate populations. Those higher in positive and negative schizotypy may be less likely to participate in social situations that involve alcohol use, due to the unusual thoughts, anhedonia, and social withdrawal that these individuals typically experience. Contrary to these past studies, positive (i.e., cognitive-perceptual) and negative forms of schizotypy were not related to use of alcohol in the present sample. However, the current study is the first to suggest a potential relationship between greater disorganized schizotypy and alcohol use in a non-psychiatric sample of young adults.

Finally, regarding cannabis use, the cognitive-perceptual and the disorganized factors were significantly related to use of this substance. Most past research has revealed significant relationships between positive schizotypy and cannabis use (Compton et al., 2007; Schiffman et al., 2005; Skosnik et al., 2006). Mass et al. (2001) found, in a sample of university students, higher levels of schizotypy as measured by the SPQ in individuals who used cannabis. The findings of the current study replicate the association between positive schizotypy and cannabis use that has been found in previous research, though the cognitive-perceptual domain was only significantly associated with one of four measures of cannabis use, namely the average number of days used per week during the past 90 days. Furthermore, the findings herein are similar to 
the results of Bailey and Swallow (2004), who discovered a positive association between disorganized schizotypy and cannabis use in a small sample of undergraduates.

In general, the fairly consistent association between the disorganized dimension of the SPQ and substance use was somewhat unexpected. Items in the odd or eccentric behavior subscale of the disorganized domain include: "Other people see me as slightly eccentric (odd)," and "People sometimes comment on my unusual mannerisms and habits.” Items in the odd speech subscale of the disorganized domain include: "People sometimes find it hard to understand what I am saying.” There are several potential explanations for this relationship between disorganized schizotypy and substance use. First, it could be that participants who engage in more frequent substance use are more likely to experience more frequent intoxication, which can manifest as behaviors that approximate disorganized schizotypy. For example, participants who are frequently intoxicated may understandably receive feedback from others describing them as odd or difficult to understand. Therefore, participants may be rating the effects of substance use rather than actual schizotypy.

Second, those participants who have high levels of schizotypy may be more likely to engage in substance use given as a function of their odd or eccentric behavior. - $\underline{\text { SuchGiven this }}$ behavior, may lead these individuals are likelyto appear strange to others, and it is hypothesized that these characteristics might lead to greater social anxiety. This social anxiety may influence individuals high in disorganized schizotypy to engage in substance use to alleviate the stress experienced in social situations. Finally, the link between disorganized schizotypy and substance use could potentially be explained by a relationship between the underlying neurobiology of subtle disorganization and the neurobiology of addictive behaviors. 
Several methodological limitations, inherent to the study design, should be considered.

First, inferences about causality should be avoided given the cross-sectional nature of the study. Second, the original factor structure of the SPQ included some overlap between the three subscales; the factor structure used in the current study (i.e., four factors) also had some overlap, such that the suspiciousness and excessive social anxiety subscales were included in both the paranoid and the negative factors (Compton et al., 2008). Third, the measure of schizotypy was based on self-report rather than researchers' ratings, and it is possible that some aspects of schizotypy may not be fully recognized by those who have such traits. Fourth, the study design utilized a web-based survey, which has inherent limitations that should be acknowledged; for example, lack of computer expertise could contribute to response errors.

Other limitations concern the generalizability of the current findings to the general population. Given that the sample was comprisedYounger individuals, such as the $\theta f$ undergraduate university students in this sample, it could be that younger individualscould display greater variability than older adults in their substance use behaviors; $;$ - for For example, college students may be more likely to engage in heavier or binge-type drinking behaviors. This greater variability in substance use behaviors has implications for detecting relationships with other variables such as personality; therefore, these findings may not generalize to other individuals who are not college students. Finally, given limited availability of comprehensive, self-administered substance use measures, the current study utilized single-item measures of substance use behavior, thus limiting our ability to conduct reliability and validity assessments.

Despite these limitations, this study is the first to examine multiple domains of schizotypy in relation to the use of several different substances using a reliable and valid measure of the multidimensional schizotypy construct. Furthermore, this study enrolled a large 
sample, a characteristic that previous research has often lacked. This not only allowed for a robust investigation of different aspects of schizotypy, but also an examination of the associations between these constructs and the use of three different substances. Future research should attempt to include standardized measures of substance use to allow for comparisons across studies, and to ensure the reliable measurement of substance use behaviors.

Other future directions for research in this area include longitudinally assessing both schizotypy and substance use to inform causal models that address the-potential reciprocal effects of subclinical psychiatric symptoms on substance use in healthy individuals, as well as how these two variables temporally relate to one another. It will be especially important to tease apart various substances to determine the differential impact of domains of schizotypy on different substances. Furthermore, given the relationship between schizotypy and schizophrenia and the high prevalence of substance use in individuals with schizophrenia, future research should attempt to examine the impact of family history of schizophrenia on the relationship between schizotypy and substance use. Finally, given that this study highlighted important links between personality variables and substance use, future research should focus on the importance of personality factors in the prevention and treatment of substance use. 


\section{References}

Allan, L.M., Williams, J.H., Wellman, N.A., Tonin, J., Taylor, E., Feldon, J. et al. (1995).

Effects of tobacco smoking, schizotypy, and number of pre-exposures on latent inhibition in healthy subjects. Personality \& Individual Differences, 19(6), 893-902.

American Psychological Association, (1980). Diagnostic and Statistical Manual of Mental

Disorders, Third Edition, Revised. Washington, DC: American Psychological

Association.

Bailey, E.L., \& Swallow, B.L. (2004). The relationship between cannabis use and schizotypal symptoms. European Psychiatry, 19, 113-114.

Chen, W.J., Hsiao, C.K., \& Lin, C.C.H., (1997). Schizotypy in community samples: The threefactor structure and correlation with sustained attention. Journal of Abnormal Psychology 106, 649-654

Compton, M.T., Goulding, S.M., McClure-Tone, E., \& Bakeman, R. (2008). Measuring schizotypy: Psychometric properties and factorial structure of three self-report rating scales in non-psychiatric young adults. Submitted for publication.

Compton, M.T., Goulding, S.M., \& Walker, E.F. (2007). Cannabis use, first-episode psychosis, and schizotypy: A summary and synthesis of recent literature. Current Psychiatry Reviews 3, 161-171. 
Conrod, P.J., Castellanos, N., \& Mackie, C. (2008). Personality-targeted interventions delay the growth of adolescent drinking and binge drinking. Journal of Child Psychology and Psychiatry, 49(2), 181-190.

Dickey, C.C., McCarley, R.W., Niznikiewicz, M.A., Voglmaier, M.A., Seidman, L.J., Kim, S. et al. (2005). Clinical, cognitive, and social characteristics of a sample of neuroleptic-naive persons with schizotypal personality disorder. Schizophrenia Research, 78, 297-308.

Dixon, L. (1999). Dual diagnosis of substance abuse in schizophrenia: prevalence and impact on outcomes. Schizophrenia Research, 35(suppl), S93-S100.

Dumas, P., Saoud, M., Bouafia, S., Gutknecht, C., Ecochard, R., Daléry, J., et al. (2002).

Cannabis use correlates with schizotypal personality traits in healthy students. Psychiatry Research 19, 27-35.

Esterberg, M.L., Jones, E.M., Compton, M.T., \& Walker, E.F. (2007). Nicotine consumption and schizotypy in first-degree relatives of individuals with schizophrenia and non-psychiatric controls. Schizophrenia Research, 97(1-3), 6-13.

Goulding, S.M., McClure-Tone, E., \& Compton, M.T. (2008). Associations between multiple dimensions of schizotypy and sociodemographic variables in a non-psychiatric sample of young adults. Submitted for publication.

Gruzelier, J.H. (1996). The factorial structure of schizotypy: Part I. Affinities with syndromes of schizophrenia. Schizophrenia Bulletin, 22, 611-620.

Hall, G., \& Habbits, P. (1996). Shadowing on the basis of contextual information in individuals with schizotypal personality. British Journal of Clinical Psychology, 35, 595-604.

Joseph, S., Manafi, E., Iakovaki, A. M., \& Cooper, R. (2003). Personality, smoking motivation, and self-efficacy to quit. Personality and Individual Differences, 34, 749-758. 
Kendler, K.S., McGuire, M., Gruenberg, A.M., \& Walsh, D. (1995). Schizotypal symptoms and signs in the Roscommon Family Study: Their factor structure and familial relationship with psychotic and affective disorders. Archives of General Psychiatry, 52, 296-303.

Larrison, A.L., Briand, K.A., \& Sereno, A.B. (1999). Nicotine, caffeine, alcohol and schizotypy. Personality \& Individual Differences, 27, 101-108.

Lenzenweger, M.F. (1998). Schizotypy and schizotypic psychopathology: Mapping an alternative expression of schizophrenia liability. In M. F. Lenzenweger \& R. H. Dworkin (Eds.), Origins and development of schizophrenia. Advances in experimental psychopathology (pp. 93-295). Washington, DC: American Psychological Association.

Mason, O., Claridge, G., \& Jackson, M. (1995) New scales for the assessment of schizotypy. PAID, 53, 727-730.

Mass, R., Bardong, C., Kindl, K., \& Dahme, B. (2001). Relationship between cannabis use, schizotypal traits, and cognitive function in healthy subjects. Psychopathology, 34, 209214.

Meehl, P.E. (1964). Manual for the use with checklist of schizotypic signs. Unpublished manuscript, University of Minnesota.

Meehl, P.E. (1990). Toward an integrated theory of schizotaxia, schizotypy, and schizophrenia. Archives of General Psychiatry, 46, 873-877.

Merritt, R.D., Balogh, D.W., \& DeVinney, S.E. (1993). Use of the MMPI to assess the construct validity of the revised Social Anhedonia Scale as an index of schizotypy. Journal of Personality Assessment, 60, 227-38.

Nunn, J.A., Rizza, F., \& Peters, E.R. (2001). The incidence of schizotypy among cannabis and alcohol users. Journal of Nervous \& Mental Disease, 189(11), 741-748. 
Peters, E., Joseph, S.R., \& Garety, P.A. (1999). The measurement of delusional ideation in the normal population: Introducing the PDI. Schizophrenia Bulletin, 25, 553-556.

Rado, S. (1960). Theory and therapy: The theory of schizotypal organization and its application to the treatment of decompensated schizotypal behavior. In S.C. Scher \& H.R. Davis (Eds), The outpatient treatment of schizophrenia (pp. 87-101). New York: Grune \& Stratton.

Raine, A. (1991). The SPQ: A scale for the assessment of schizotypal personality based on DSM-III-R criteria. Schizophrenia Bulletin, 17, 555-564.

Raine, A., Lencz, T., \& Mednick, S.A. (Eds.) (1995). Schizotypal personality disorder. Cambridge: Cambridge University Press.

Raine, A., Reynolds, C., Lencz, T., Scerbo, A., Triphon, N., \& Kim, D. (1994). Cognitiveperceptual, interpersonal, and disorganized features of schizotypal personality. Schizophrenia Bulletin, 20, 191-201.

Reynolds, C.A., Raine, A., Mellingen, K., Venables, P.H., \& Mednick, S.A. (2000). Three-factor model of schizotypal personality: Invariance across culture, gender, religious affiliation, family adversity, and psychopathology. Schizophrenia Bulletin, 26, 603-618.

Rust, J. (1988). The Rust inventory of schizotypal cognitions (RISC). Schizophrenia Bulletin, 14 (2), 317-322.

Schiffman, J., Nakamura, B., Earleywine, M., \& LaBrie, J. (2005). Symptoms of schizotypy precede cannabis use. Psychiatry Research, 134, 37-42.

Skosnik, P.D., Krishnan, G.P., Aydt, E.E., Kuhlenshmidt, H.A., \& O’Donnell, B.F. (2006). Psychophysiological evidence of altered neural synchronization in cannabis use: Relationship to schizotypy. American Journal of Psychiatry, 163, 1798-1805. 
Stefanis, N.C., Smyrnis N., Avramopoulos, D., Evdokimidis, I., Ntzoufras, I., \& Stefanis, C.N. (2004). Factorial composition of self-rated schizotypal traits among young males undergoing military training. Schizophrenia Bulletin, 30, 335-350.

Substance Abuse and Mental Health Services Administration, Office of Applied Studies (2008). Results from the 2007 National Survey on Drug Use and Health: National Findings (NSDUH Series H-34, DHHS Publication No. SMA 08-4343). Rockville, MD.

Wiles, N.J., Zammit, S., Bebbington, P., Singleton, N., Meltzer, H., \& Lewis, G. (2006). Selfreported psychotic symptoms in the general population. Results from the longitudinal study of the British National Psychiatric Morbidity Study. British Journal of Psychiatry, $188,519-526$. 
Table 1. Sociodemographic, schizotypy, and substance use characteristics of sample $(n=825)$

\begin{tabular}{|c|c|c|c|c|c|}
\hline Characteristic & $\begin{array}{c}\text { Mean } \pm \text { SD } \\
(\%)\end{array}$ & Range & Characteristic & $\begin{array}{c}\text { Mean } \pm \text { SD } \\
(\%)\end{array}$ & Range \\
\hline Age & $20.1 \pm 1.7$ & $18-25.9$ & Lifetime use of cigarettes & $47.8 \%$ & -- \\
\hline Sex (Female) & $77.2 \%$ & -- & $\begin{array}{l}\text { Use of cigarettes in past } 90 \text { days (of } \\
\text { those who have used) }\end{array}$ & $54.8 \%$ & - \\
\hline Race (Caucasian) & $46.4 \%$ & -- & Age at first use of cigarettes & $15.6 \pm 2.7$ & $6-23$ \\
\hline Race (African American) & $30.8 \%$ & -- & $\begin{array}{l}\text { Average days/week used cigarettes in } \\
\text { past } 90 \text { days }\end{array}$ & $0.9 \pm 2.2$ & $0-7$ \\
\hline Race (Other) & $22.8 \%$ & $\overline{--}$ & Lifetime use of alcohol & $81.1 \%$ & -- \\
\hline SPQ Total & $22.9 \pm 13.6$ & $0-74$ & $\begin{array}{l}\text { Use of alcohol in past } 90 \text { days (of those } \\
\text { who have used) }\end{array}$ & $79.7 \%$ & -- \\
\hline SPQ Cognitive-perceptual & $3.9 \pm 3.4$ & $0-16$ & Age at first use of alcohol & $15.9 \pm 2.5$ & $2-22$ \\
\hline SPQ Paranoid & $9.8 \pm 5.6$ & $0-25$ & $\begin{array}{l}\text { Average days/week used alcohol in past } \\
90 \text { days }\end{array}$ & $1.2 \pm 1.5$ & $0-7$ \\
\hline SPQ Negative & $9.9 \pm 6.8$ & $0-33$ & Lifetime use of cannabis & $42.1 \%$ & -- \\
\hline \multirow[t]{3}{*}{ SPQ Disorganized } & $5.3 \pm 4.1$ & $0-16$ & $\begin{array}{l}\text { Use of cannabis in past } 90 \text { days (of } \\
\text { those who have used) }\end{array}$ & $53.3 \%$ & -- \\
\hline & & & Age at first use of cannabis & $16.3 \pm 2.5$ & $8-24$ \\
\hline & & & $\begin{array}{l}\text { Average days/week used cannabis in } \\
\text { past } 90 \text { days }\end{array}$ & $0.7 \pm 1.7$ & $0-7$ \\
\hline
\end{tabular}


Table 2. Intercorrelations among schizotypy domains

\begin{tabular}{lccc}
\hline Schizotypy Domain & SPQ Cognitive-perceptual & SPQ Paranoid & SPQ Negative \\
\hline SPQ Cognitive-perceptual & & & \\
\hline SPQ Paranoid & $0.52^{*}$ & & \\
\hline SPQ Negative & $0.43^{*}$ & $0.84^{*}$ & \\
& & $0.56^{*}$ & $0.58^{*}$ \\
\hline SPQ Disorganized & $0.55^{*}$ & &
\end{tabular}

* Correlation significant at $p<0.001$ 
Table 3. Intercorrelations and chi-square values for relationships among substance use variables

\begin{tabular}{|c|c|c|c|c|c|c|c|c|c|c|c|c|}
\hline $\begin{array}{l}\text { Substance } \\
\text { Use Variable }\end{array}$ & 1 & 2 & 3 & 4 & 5 & 6 & 7 & 8 & 9 & 10 & 11 & 12 \\
\hline 1 & & & & & $120.63 * *$ & $-0.31^{* *}$ & $103.43 * *$ & $0.35^{* *}$ & $247.89 * *$ & $-0.22 * *$ & $108.43^{* *}$ & $0.29 * *$ \\
\hline 2 & & & 0.02 & -0.04 & -0.08 & $0.41^{* *}$ & -0.03 & -0.01 & -0.08 & $0.60^{* *}$ & -0.08 & $-0.16^{*}$ \\
\hline 3 & & 0.02 & & & $39.35 * *$ & $-0.19 * *$ & 84.33** & $0.34 * *$ & $140.68 * *$ & $-0.17^{*}$ & 111.31** & $0.37 * *$ \\
\hline 4 & & -0.04 & & & $0.19 * *$ & $-0.17 * *$ & $0.25 * *$ & $0.33 * *$ & $0.39 * *$ & $-0.19 * *$ & $0.32 * *$ & $0.39 * *$ \\
\hline 5 & $120.63^{* *}$ & -0.08 & $39.35^{* *}$ & $0.19 * *$ & & & & & $110.27 * *$ & -0.01 & $40.49 * *$ & $0.17 * *$ \\
\hline 6 & $-0.31^{* *}$ & $0.41 * *$ & $-0.19 * *$ & $-0.17^{* *}$ & & & $-0.15^{* *}$ & $-0.18^{* *}$ & $-0.29 * *$ & $0.47^{* *}$ & $-0.24 * *$ & $-0.21 * *$ \\
\hline 7 & $103.43^{* *}$ & -0.03 & 84.33** & $0.25^{* *}$ & & $-0.15^{* *}$ & & & $136.92 * *$ & -0.09 & $104.21 * *$ & $0.25^{* *}$ \\
\hline 8 & $0.35^{* *}$ & -0.01 & $0.34 * *$ & $0.33^{* *}$ & & $-0.18^{* *}$ & & & $0.42 * *$ & $-0.12^{*}$ & $0.32 * *$ & $0.36^{* *}$ \\
\hline 9 & $247.89 * *$ & $\begin{array}{l}-0.08 \\
\end{array}$ & $140.68 * *$ & $0.39 * *$ & $110.27 * *$ & $-0.29 * *$ & $136.91 * *$ & $0.42 * *$ & & & & \\
\hline 10 & $-0.22^{* *}$ & $0.60 * *$ & $-0.17 * *$ & $-0.19 * *$ & -0.01 & $0.47 * *$ & -0.09 & $-0.12^{*}$ & & & $-0.12^{*}$ & $-0.26^{* *}$ \\
\hline 11 & $108.43^{* *}$ & $\begin{array}{l}-0.08 \\
\end{array}$ & $111.31^{* *}$ & $0.32 * *$ & $40.49 * *$ & $-0.24^{* *}$ & $104.21 * *$ & $0.32 * *$ & & $-0.12 *$ & & \\
\hline 12 & $0.29 * *$ & $-0.16^{* *}$ & $0.37 * *$ & $0.39 * *$ & $0.17 * *$ & $-0.21^{* *}$ & $0.25^{* *}$ & $0.36 * *$ & & $-0.26^{* *}$ & & \\
\hline $\begin{array}{ll}1 & \text { Lifetime use } \\
2 & \text { Age at first } \\
3 & \text { Used cigaret } \\
4 & \text { Average day } \\
5 & \text { Lifetime use } \\
6 & \text { Age at first u }\end{array}$ & $\begin{array}{l}\text { f cigarettes } \\
\text { of cigarettes } \\
\text { s in past } 90 \text { de } \\
\text { per week usec } \\
\text { f alcohol } \\
\text { of alcohol }\end{array}$ & $\begin{array}{l}\text { s } \\
\text { cigarettes }\end{array}$ & & $\begin{array}{ll}7 & \text { Used al } \\
8 & \text { Averag } \\
9 & \text { Lifetim } \\
10 & \text { Age at } \\
11 & \text { Used ca } \\
12 & \text { Averag }\end{array}$ & $\begin{array}{l}\text { ohol in past } \\
\text { days per wee } \\
\text { use of canna } \\
\text { rst use of can } \\
\text { nabis in past } \\
\text { days per wee }\end{array}$ & $\begin{array}{l}\text { days } \\
\text { used alcohol } \\
\text { is } \\
\text { abis } \\
0 \text { days } \\
\text { used cannab }\end{array}$ & & $\begin{array}{l}* \mathrm{Si} \\
{ }^{* *} \mathrm{Si} \\
\text { Bolde }\end{array}$ & $\begin{array}{l}\text { hificant at } \mathrm{p}< \\
\text { hificant at } \mathrm{p}< \\
\text { values repres }\end{array}$ & $\begin{array}{l}.05 \\
.01 \\
\text { nt chi-squa }\end{array}$ & values & \\
\hline
\end{tabular}


Table 4. Results of linear and logistic regression analyses pertaining to four schizotypy domains and nicotine use

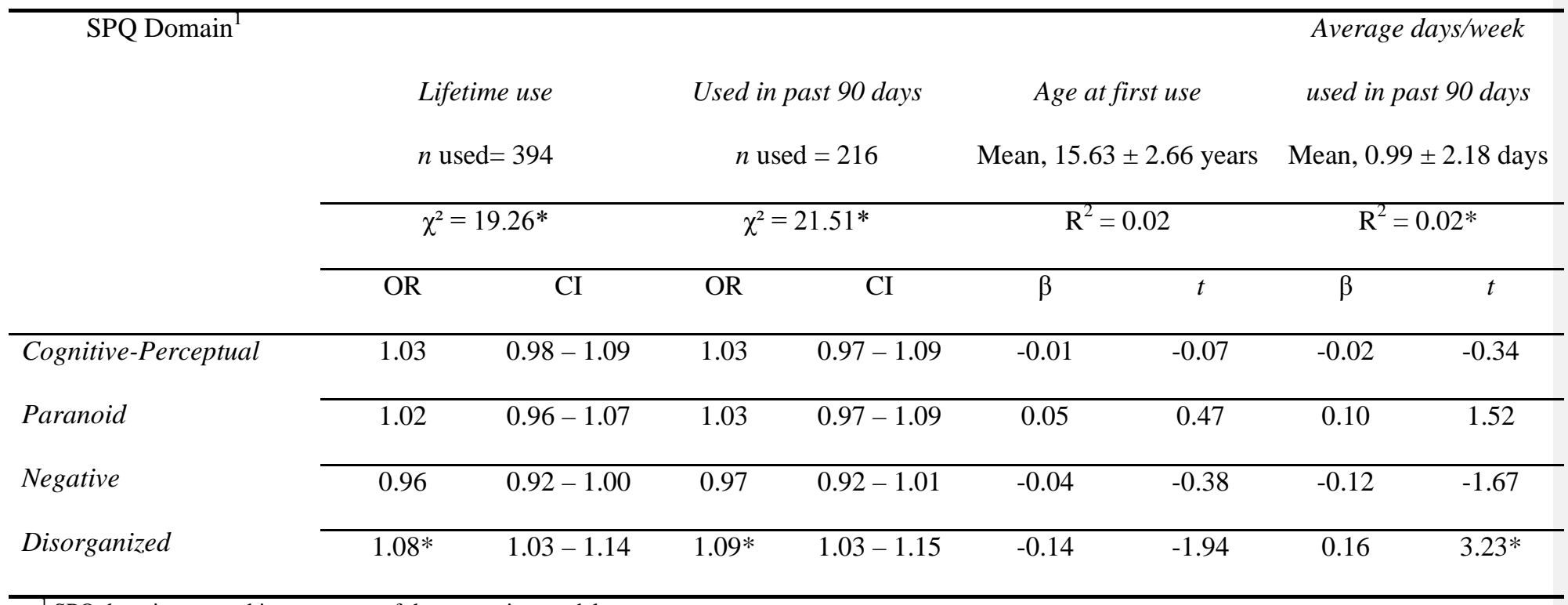

${ }^{1}$ SPQ domains entered into one step of the regression model

* Significant at $p<0.01$ 
Table 5. Results of linear and logistic regression analyses pertaining to four schizotypy domains and alcohol use

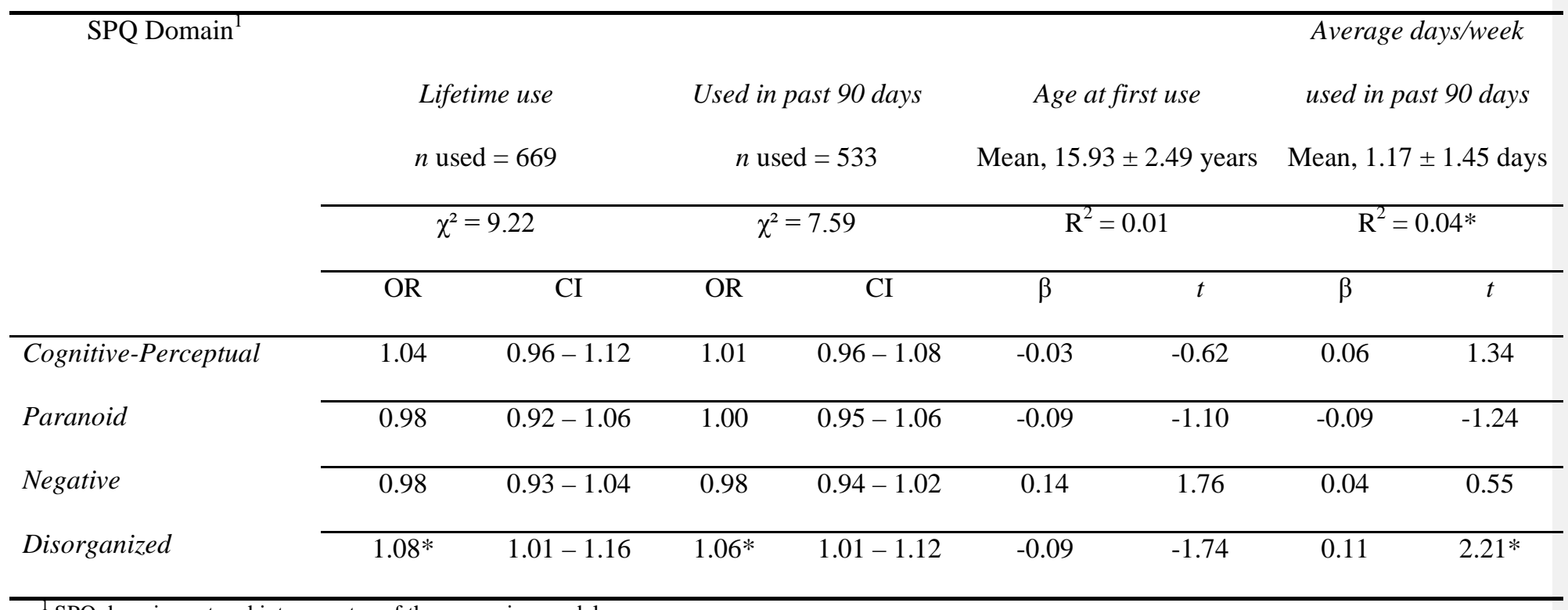

${ }^{1}$ SPQ domains entered into one step of the regression model

* Significant at $p<0.05$ 
Table 6. Results of linear and logistic regression analyses pertaining to four schizotypy domains and cannabis use

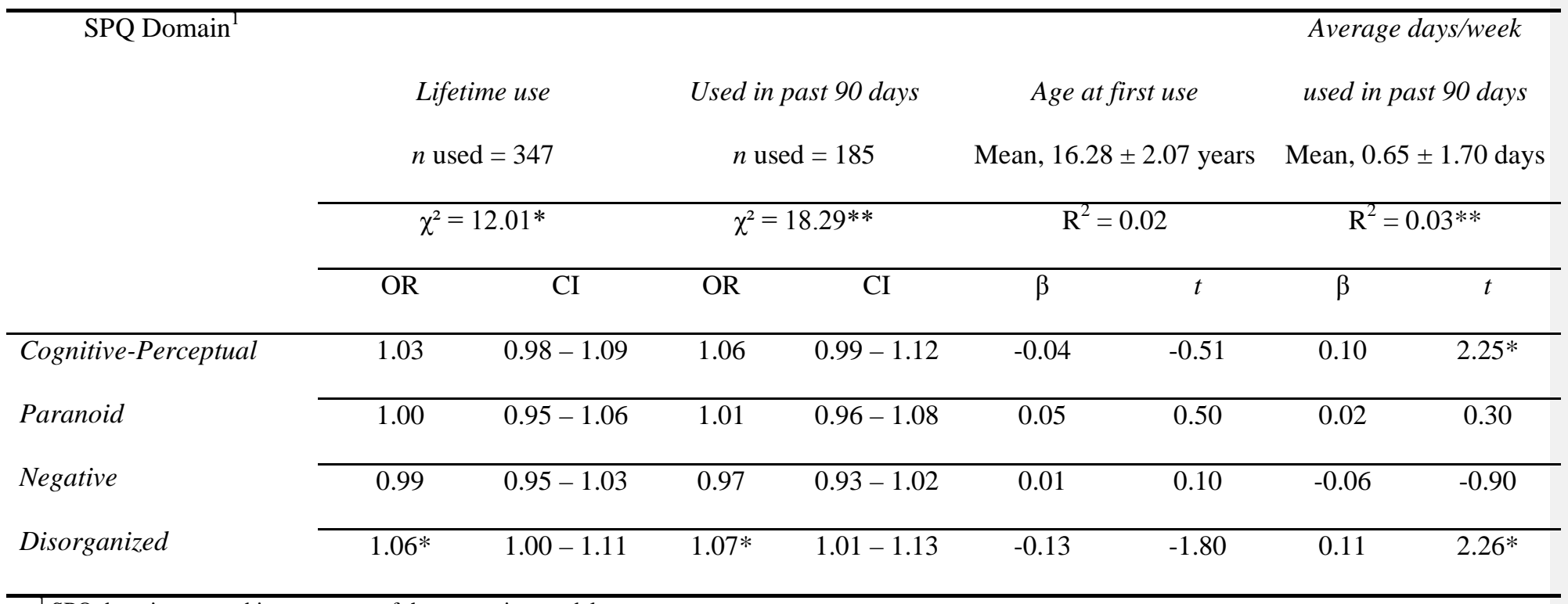

${ }^{1}$ SPQ domains entered into one step of the regression model

* Significant at $p<0.05$

** Significant at $p<0.01$ 